\title{
A narrative review of the challenges and countermeasures in hepatoblastoma management during COVID-19 epidemic
}

\author{
Hang Xu ${ }^{1 \#}$, Yan Zhou ${ }^{1,2 \#}$, Rui Sun ${ }^{1,2}$, Xuelai Liu ${ }^{1}$, Mei Diao ${ }^{1,2}$, Xianghai Ren ${ }^{3}$, Long Li ${ }^{1,2}$ \\ ${ }^{1}$ Department of Pediatric Surgery, Capital Institute of Pediatrics, Beijing, China; ${ }^{2}$ Graduate School of Peking Union Medical College, Chinese \\ Academy of Medical Sciences, Beijing, China; ${ }^{3}$ Department of Colorectal and Anal Surgery, Zhongnan Hospital of Wuhan University, Wuhan, China \\ Contributions: (I) Conception and design: H Xu, Y Zhou; (II) Administrative support: X Ren, L Li, M Diao; (III) Provision of study materials or \\ patients: All authors; (IV) Collection and assembly of data: All authors; (V) Data analysis and interpretation: All authors; (VI) Manuscript writing: All \\ authors; (VII) Final approval of manuscript: All authors. \\ \#These authors contributed equally to this work. \\ Correspondence to: Xianghai Ren, MD, PhD. Department of Colorectal and Anal Surgery, Zhongnan Hospital of Wuhan University, Wuhan 430071, \\ China. Email: xianghai_ren@qq.com; Long Li, MD, PhD. Department of Pediatric Surgery, Capital Institute of Pediatrics, No. 2 Yabao Road, \\ Chaoyang District, Beijing 100071, China. Email: lilong3@hotmail.com.
}

\begin{abstract}
An infectious disease named "coronavirus disease 2019" (COVID-19) currently has brought a threat to global health security and trends to be more and more severe in many countries. It also has introduced great challenges to the diagnosis and management of children with hepatoblastoma (HB). During the COVID-19 pandemic, pediatric surgeons should not only develop personalized treatment plans for HB therapy, but also emphasize the diagnosis, prevention, and treatment of this virus. Children with both $\mathrm{HB}$ and COVID-19 are recommended to undertake multidisciplinary assessment. Anti-SARS-CoV-2 therapy may be a preferred treatment for the infected without presenting a surgical emergency. However, emergent operation may be necessary for HB children with concurrent COVID-19 who developed a life-threatening surgical emergency condition. Otherwise, for children with negative virus examination results, treatment advice should be based on the impact of the epidemic and regional economic considerations. A "wait and see" strategy is recommended for children with resectable tumors after new adjuvant chemotherapy treatment (NACT). Assessment of liver transplantation is recommended for children with HB whose tumors cannot be resected after NACT. Children with HB with pulmonary metastasis may have abnormal findings on chest imaging due to COVID-19. Besides, the detailed therapeutic regimens may vary for children with HB with or without an emergency presentation. Based on previous consensus, current research, and the experiences of our hospital, we aim to offer available management plans for the above-mentioned concerns.
\end{abstract}

Keywords: Coronavirus disease 2019 (COVID-19); severe acute respiratory syndrome coronavirus 2 (SARSCoV-2); hepatoblastoma

Submitted May 18, 2020. Accepted for publication Oct 22, 2020.

doi: $10.21037 /$ tp-20-143

View this article at: http://dx.doi.org/10.21037/tp-20-143

\section{Introduction}

An infectious disease named "coronavirus disease 2019" (COVID-19) currently poses a threat to global health security $(1,2)$. Although the urgent and aggressive actions taken in China resulted in a continuous and steady decrease in the number of confirmed cases nationwide, America has become the new epicenter of the COVID-19 pandemic, as more cases are being reported on the continent every day. As of September 20, 2020, there were 31,047,639 cases across 196 countries and 961,821 people who have lost their lives (3). Unfortunately, America $(\mathrm{n}=6,967,403)$, India 


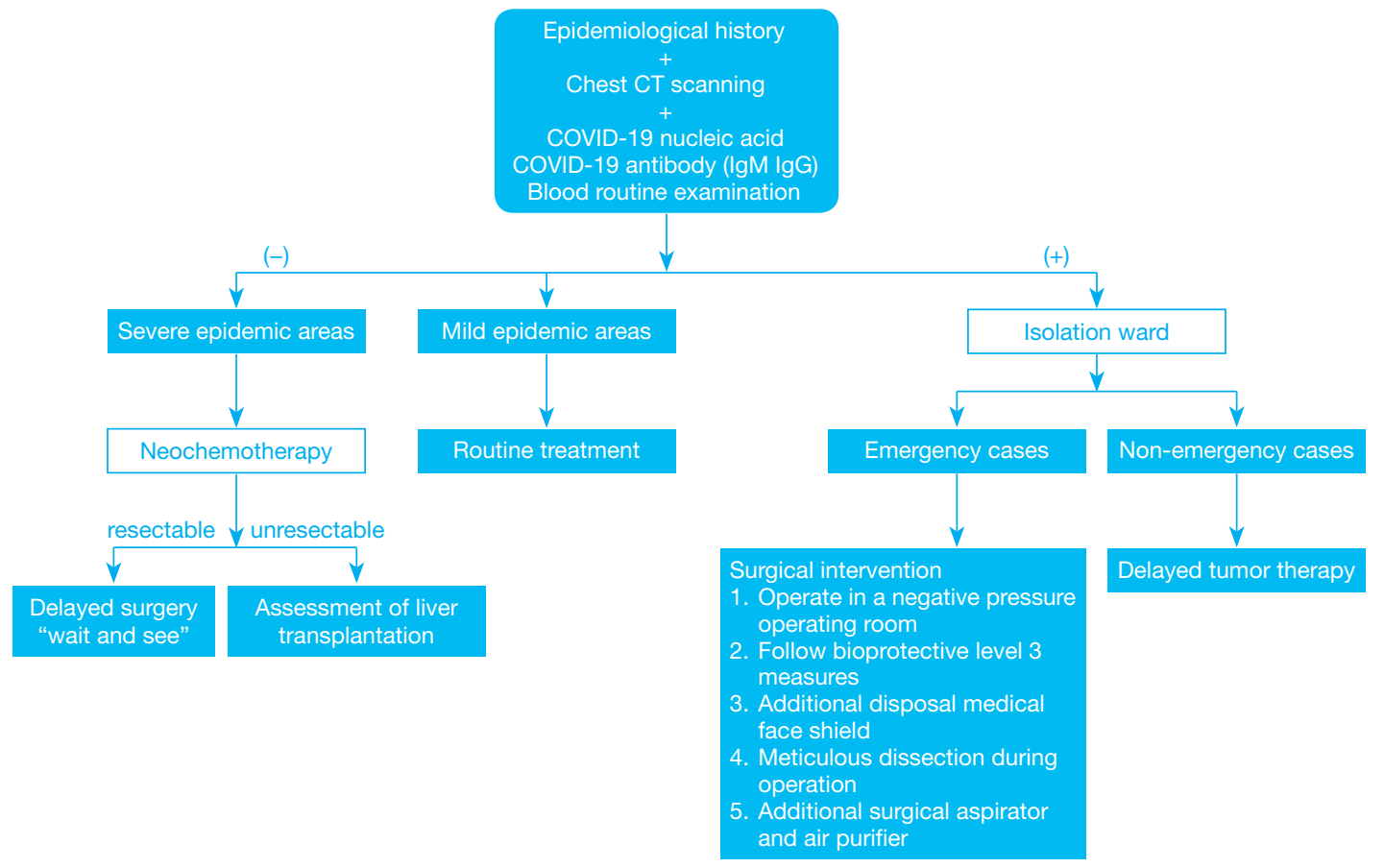

Figure 1 A flowchart of the recommended management protocol.

$(\mathrm{n}=5,400,619)$, and Brazil $(\mathrm{n}=4,528,240)$ have the highest number of confirmed cases.

Hepatoblastoma (HB), which usually affects patients $<3$ years old, is the most common malignant liver tumor in children, with an incidence rate of $1.2-1.5$ per million people (4). Although some studies have claimed that children may be less susceptible to COVID-19, the true rate of severe acute respiratory syndrome coronavirus 2 (SARS-CoV-2) infection should not be understated because many children with asymptomatic or mild infections may be unlikely to be tested (5). In addition, as a wasting disease, $\mathrm{HB}$ itself and its corresponding treatment may weaken the immune response to pathogenic microorganisms, increase the likelihood of coronavirus infection (for uninfected children), or worsen COVID-19 (for infected children) (6). Furthermore, the relative shortage of medical resources caused by a surge in the number of patients with COVID-19 and the economic downturn may affect the therapeutic methods available for children with HB. Therefore, in the context of the current COVID-19 pandemic, the management of children with HB deserves attention.

Here, we discuss the diagnosis and management of patients with HB during the COVID-19 pandemic based on previous guidelines, the current working status, and our experiences, to provide a reference for clinical practitioners. The flowchart of this paper is shown in Figure 1. We present the following article in accordance with the Narrative Review reporting checklist (available at http:// dx.doi.org/10.21037/tp-20-143).

\section{Screening and diagnosis of hepatoblastoma}

A rigid epidemiological history of patients and their parents is required, including whether (I) they have been to epidemic focus areas within 14 days; (II) there is a history of travel or residence in a community and surrounding areas with COVID-19 cases reported; (III) there has been contact with confirmed/suspected cases or people from infected areas; (IV) they have any respiratory symptoms such as fever, cough, and dyspnea; and (V) they have a history of wild animal exposure (7). Chest imaging examination is recommended for outpatients in epidemic areas. Suspected SARS-COV-2-infected cases are diagnosed according to the children's epidemiological history, COVID-19 nucleic acid, COVID-19 antibody (IgM/IgG), and clinical manifestations $(8,9)$. However, we should be aware of the potential falsenegative results of temperature checking and imagological findings. Virus detection may also be negative in the early stages of infection. A recent report showed that $15.8 \%$ of 
infected children had no abnormality on chest computed tomography (CT), and only $41.5 \%$ of children presented with fever during infection. Therefore, imagological examination combined with virus detection may represent the highest sensitivity for children with COVID-19.

After ruling out SARS-CoV-2 infection, children will be transferred to the pediatric surgery department for further diagnosis and treatment. After physical examination and collection of their detailed history, a blood specimen should be collected for routine blood tests, liver function tests, and tumor markers [such as alpha fetoprotein $(\alpha \mathrm{FP})$ ]. Imaging examinations, including abdominal ultrasound and contrastenhanced CT, can be performed when HB is suspected. Although biopsy tissue may not reflect the entire tumor, biopsy before treatment not only confirms the diagnosis but also provides important information that will contribute towards therapeutic decision-making. Hence, for children without confirmed/suspected SARS-CoV-2 infection, a biopsy should be performed before treatment. However, for children with confirmed/suspected COVID-19, although some children are asymptomatic or present with mild symptoms, the virus may "awaken" and symptoms may worsen with the progression of SARS-CoV-2 infection; therefore, a short delay in biopsy and priority treatment for infection seems to be beneficial to the overall condition of children (10).

The lung is the most common distant metastatic site for hepatoblastoma (11). Patients with HB with lung metastasis may show imaging findings similar to those of children with SARS-CoV-2 infection. These deceptive symptoms can be differentiated by viral nucleic acid tests, CT imaging, and tumor markers. More than one non-calcified nodule $>5 \mathrm{~mm}$ in diameter, or multiple nodules $>3 \mathrm{~mm}$ in diameter may be found via imaging findings of pulmonary metastasis for $\mathrm{HB}$, while in children with SARS-CoV-2-related pneumonia, lung imaging often manifests as subpleural ground-glass opacities and consolidations with a surrounding halo $(12,13)$. Furthermore, fever is one of the features of patients with HB presenting with tumor rupture. In addition, neutropenia and other side effects caused by chemotherapy as well as $\mathrm{HB}$ itself can lead to fever, which also needs to be discriminated from the fever caused by SARS-CoV-2 infections (14). A detailed chemotherapy history of the patient should be collected to differentiate the complications and tumorrelated fever during chemotherapy from viral infection. Given this special period, the current multidisciplinary team (MDT) should be composed of departments of pediatric surgery, radiotherapy, gastroenterology, nutrition, pathology, urology department, respiratory department, and infectious department pediatric intensive care unit (PICU) (8). The main tasks of the MDT are as follows:

(I) Avoiding misdiagnosis and missed diagnosis of SARS-CoV-2 infection and cross-infection;

(II) Completing HB diagnosis collaboratively with existing medical resources;

(III) Providing optimal individualized treatment to maximize the clinical benefit to patients;

(IV) Developing a well-designed follow-up strategy and providing online clinical consultations;

(V) Psychological counseling and providing a psychological crisis intervention.

\section{Treatment strategies for patients with HB during the COVID-19 pandemic}

During the COVID-19 pandemic, although the principles of tumor therapy remain unchanged, the detailed therapeutic methods for patients with HB may be different from the norm. Specific guidelines for HB treatment may vary depending on whether the children are infected or not. In addition to tumor therapy, promoting COVID-19 prevention (for non-SARS-CoV-2 infected patients) and rehabilitation (for SARS-CoV-2 patients infected) should be two other main treatment focuses. Since caregivers of children and health workers in departments of pediatrics may be a potentially essential source of COVID-19, measures to prevent in-hospital infection should also be valued, which includes: (I) arranging nucleic acid screening for all the medical personnel during hospitalization; (II) carrying out regular disinfection of the wards; (III) decreasing the flow and number of accompanying personnel; (IV) reducing the number of ward beds, and ensure the space between beds as far as possible.

\section{Children with HB and confirmed/suspected COVID-19}

Confirmed/suspected COVID-19 cases with HB should be directly transferred to an isolated ward. Since the incubation period of COVID-19 for most children ranges from 3-14 days, children with suspected infection should be quarantined for at least 14 days (15). To learn about both the tumor condition and infection status, dynamic assessment and clinical observation of the patient is required. For nonemergency cases, the priority of treating COVID-19 and delay in tumor therapies (including chemotherapy, surgical resection, and liver transplantation) for infected children 
with $\mathrm{HB}$ may be a good option for the following reasons: (I) chemotherapy and surgery may cause damage to a child's immune system, so it may exacerbate the progression of COVID-19 (16). The prognosis for SARS-CoV-2-infected children with preexisting diseases may be worse than those with SARS-CoV-2 infection alone. A recent report showed that the case-fatality rate was higher in patients with preexisting cancers compared to the overall rate (5.6\% vs. $2.3 \%)(17,18)$. (II) More children than adults may initially be asymptomatic or present with mild symptoms, most likely due to underdeveloped angiotensin-converting enzyme 2 (ACE2) protein which binds the $\mathrm{S}$ protein of 2019-nCoV virus, and a healthier respiratory tract due to less exposure time to cigarette smoke and air pollution; however, the possibility of later exacerbation of symptoms should not be excluded (14). Therefore, we should not be misguided by mild or asymptomatic characteristics when developing the treatment plan. (III) Although there has been no large sample of children's case data to determine the course of COVID-19 in children, Chen et al. (19) analyzed the data of 248 adult patients, of whom the estimated median time from initiation of symptoms to PCR negativity was 11 days. Therefore, a short delay in $\mathrm{HB}$ therapy may have no remarkable influence on the prognosis of patients with $\mathrm{HB}$, and the MDT is responsible for deciding the timing of oncotherapy initiation/re-initiation.

However, for emergency cases such as ruptured HB, prompt surgical intervention may be required. Tumor rupture is listed as a high-risk group with poor prognosis by the International Society of Pediatric Oncology - Liver Tumor Strategy Group (SIOPEL) (20,21). Although emergency surgery may be a risky practice in children with concurrent SARS-CoV-2 infection, it may still be the only life-saving procedure for those who develop uncontrolled massive bleeding (22). Undoubtedly, treating these patients brings great challenges to the MDT, especially in the PICU, department of anesthesiology, and pediatric surgeons.

We recommend emergency surgery for confirmed/ suspected cases of SARS-CoV-2 infection to be operated in a negative pressure $(-5 \mathrm{~Pa})$ operating room $(\mathrm{OR})$ of a designated hospital. All doctors and nurses involved should follow bioprotective level 3 measures, including wearing medical cups, an N95 or higher respirator, medical coveralls, eye shield, surgical latex gloves, disposable operating coat, protective hood, and waterproof and disposable shoe covers. Anesthesiologists should wear an additional disposable medical face shield to protect against the coughing of children during trachea intubation and extubation. Apart from airborne and contact transmission, aerosols may be another potential route of SARS-CoV-2 infection (23). Hence, during the operation, operators should dissect meticulously to avoid splashing of bodily fluids. Smoke produced by high-frequency electrotomes and ultrasonic knives can mix with the blood and exudate of infected children to form aerosols and diffuse into the surrounding air. Therefore, using an additional surgical aspirator and placing an air purifier in the OR may be potential ways to reduce the risk of aerosol transmission. As mentioned above, in emergency $\mathrm{HB}$ cases with SARS-CoV-2 infection, aggressive radical resection could further compromise a child's immune system. For those patients who present with relatively severe COVID-19 symptoms or advanced tumors, it may be appropriate to resolve the emergency problem immediately and delay tumor resection until the child's recovery from infection (24). After the operation, the OR should be completely disinfected and closed for at least two hours. Postoperative monitoring of vital signs (monitored emphatically), oxygen therapy, antivirals, and nutritional supplementation for children may be recommended. Chest $\mathrm{CT}$ and virus detection will be repeated according to the suggestion of the respiratory/infection department.

\section{Patients with HB without COVID-19}

Tumor treatment, providing psychological comfort, and preventing SARS-CoV-2 infection should be the main treatment principles for treating patients with $\mathrm{HB}$ without SARS-CoV-2 infection.

In severe epidemic areas, many doctors and wards are dedicated to treating COVID-19, which may influence the diagnosis and treatment of many children with HB (25). Although the recent Pediatric Hepatic International Tumor Trial (PHITT) surgical guidelines recommend that children with HB in PRETEXT I or select PRETEXT II (with $\geq 1 \mathrm{~cm}$ radiographic margin from the middle hepatic vein, retro-hepatic inferior vena cava, and portal bifurcation) groups undergo primary resection without the need for neoadjuvant chemotherapy (NACT), some children with HB may have no opportunity to receive timely surgical treatment. If this is the case, according to the therapeutic regimen from SIOPEL, giving all children with HB NACT and then preforming delayed surgery may be an option $(26,27)$. As an effective "bridge" therapy during the current pandemic, NACT could effectively shrink the size of the tumor and even achieve downstaging. A report from SIOPEL-4 showed that $98 \%$ of children with high- 
Table 1 The recommendations of neoadjuvant chemotherapy in different study groups

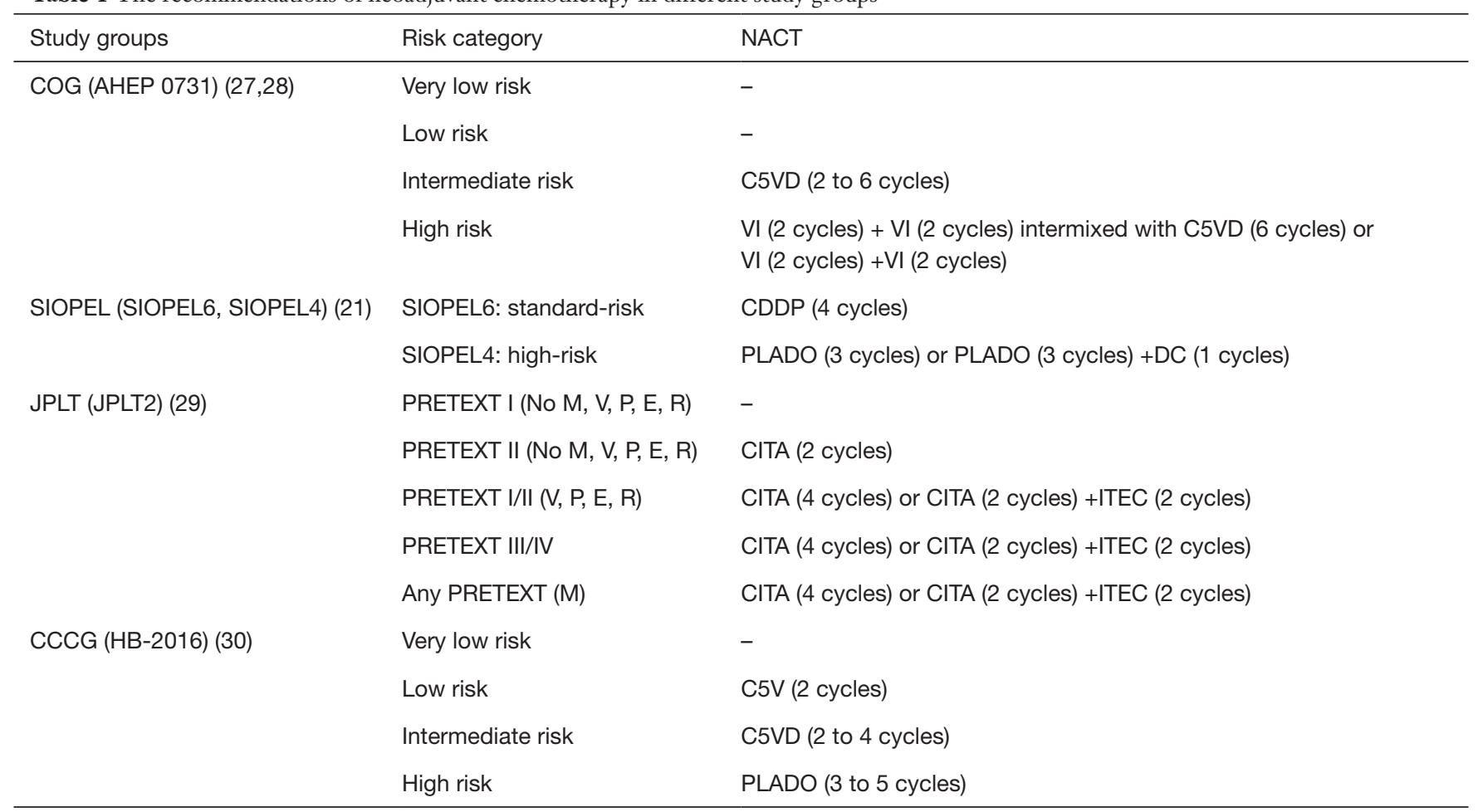

C5V, cisplatin/5-fluorouracil/vincristine; C5VD, cisplatin/5-fluorouracil/vincristine/doxorubicin; CCCG, Chinese Anti-Cancer Association Pediatric Committee; CDDP, cisplatin; CITA, cisplatin/pirarubicin; COG, Children's Oncology Group; DC, doxorubicin/carboplatin; E, extrahepatic factors; H, tumor rupture; HB, hepatoblastoma; ITEC, ifosfamide/pirarubicin/etoposide/carboplatin; JPLT, Japanese Pediatric Liver Tumor Study Group; M, distant metastasis; N, lymph node metastasis; NACT, neoadjuvant chemotherapy; P+, involvement of main portal vein, its bifurcation, or both of its main branches; PRETEXT, PRE-Treatment EXTent of tumor; PLADO, cisplatin/doxorubicin; SIOPEL, International Society of Pediatric Oncology-Liver Tumor Strategy Group; V+, involvement of all three hepatic veins or the vena cava.

risk $\mathrm{HB}$ achieved partial resonance (any tumor volume shrinkage and decrease of alpha-fetoprotein (AFP) > $1 \log$ from the original value) with NACT. In addition, data from SIOPEL-3 indicated that the partial response (any tumor shrinkage and serial decrease in the serum AFP value) rate was over $90 \%$ for children with standard-risk HB $(26,28)$. Generally speaking, the number of cycles of NACT ranged from 2-10 for those who needed preoperative chemotherapy, according to the Children's Oncology Group (COG; AHEP 0371), SIOPLE (SIOPLE 4 and 6), the Japanese Study Group for Pediatric Liver Tumor (JPLT; JPLT 2), and Chinese Anti-Cancer Association Pediatric Committee (CCCG-HB-2016) (Table 1) (21,27-33).

The CCCG-HB-2016 classified HB patients into very low-, low-, mediate-, and high-risk groups based on the risk stratifications of COG, SIOPEL, and the pathological findings (Table 2) (20,33-36).

As mentioned above, surgery may weaken the immune response to the virus. However, surgery is still the mainstay of treatment for children with HB. The COVID-19 pandemic may last for months, and a prolonged delay in cancer treatment may be associated with worse outcomes. We should not suspend cancer treatment indefinitely in uninfected children for fear of infection. If resection was deemed possible after NACT, children should undergo surgery with minimal delay. Children with $\mathrm{HB}$ who remain unresectable after NACT can be candidates for liver transplantation (LT) (37-40). However, the cost and benefits of performing LT within an epidemic region should be carefully assessed. LT may lead to the transmission of viral infection from donor to recipient, and immunosuppressive therapy post-transplant may increase the risk of severe infection with poor outcomes. Whether LT should be performed during the COVID-19 pandemic remains unanswered $(32,33)$.

Approximately $20 \%$ of children initially diagnosed 
Table 2 Risk stratifications from different study groups

\begin{tabular}{|c|c|}
\hline Groups & Details \\
\hline \multicolumn{2}{|l|}{ SIOPEL group } \\
\hline Standard risk & PRETEXT I or II or III, and AFP $\geq 100(\mathrm{ng} / \mathrm{mL})$ \\
\hline High risk & $\begin{array}{l}\text { Any of the following: } \\
\text { - PRETEXT IV } \\
\text { - Any PRETEXT, and E+ V+ P+ M+ N+ H+ } \\
\text { - Any PRETEXT, and AFP <100 (ng/mL) }\end{array}$ \\
\hline \multicolumn{2}{|l|}{ COG group } \\
\hline Very low risk & COG stage 1 , and PFH \\
\hline Low risk & $\begin{array}{l}\text { Any of the following: } \\
\text { - COG stage 1, and non-PFH or non SCU } \\
\text { - COG stage 2, and non SCU }\end{array}$ \\
\hline $\begin{array}{l}\text { Intermediate } \\
\text { risk }\end{array}$ & $\begin{array}{l}\text { Any of the following: } \\
\text { - COG stage } 1 \text { or } 2 \text {, and SCU } \\
\text { - COG stage } 3\end{array}$ \\
\hline High risk & $\begin{array}{l}\text { Any of the following: } \\
\text { - COG stage } 4 \\
\text { - Any stage, and AFP <100 (ng/mL) }\end{array}$ \\
\hline \multicolumn{2}{|l|}{ JPLT Group } \\
\hline Standard risk & PRETEXT I or II \\
\hline High risk & $\begin{array}{l}\text { Any of the following: } \\
\text { - PRETEXT III or IV } \\
\text { - Any PRETEXT, and E+ V+ P+M+ N+ H+ }\end{array}$ \\
\hline \multicolumn{2}{|c|}{ CCCG (HB) Group } \\
\hline Very low risk & COG stage 1, and PFH \\
\hline Low risk & $\begin{array}{l}\text { Any of the following: } \\
\text { - PRETEXT I or II, and AFP } \geq 100(\mathrm{ng} / \mathrm{mL}) \\
\text { - COG stage } 1 \text { or } 2 \text {, and non-PFH or non } \\
\text { SCU }\end{array}$ \\
\hline $\begin{array}{l}\text { Intermediate } \\
\text { risk }\end{array}$ & $\begin{array}{l}\text { Any of the following: } \\
\text { - PRETEXT III } \\
\text { - COG stage } 1 \text { or } 2 \text {, and SCU } \\
\text { - COG stage } 3\end{array}$ \\
\hline
\end{tabular}

Table 2 (continued)
Table 2 (continued)

\begin{tabular}{ll}
\hline Groups & Details \\
\hline High risk & Any of the following: \\
& - AFP $<100$ (ng/mL) \\
- PRETEXT IV & COG stage 4 \\
• V+ P+
\end{tabular}

with HB presented with lung metastasis (34). Fortunately, more than half of patients achieved complete remission of pulmonary metastases (20). Of the remaining children without regression of the metastatic site, an additional metastasectomy should be scheduled. Since children with metastatic HB may have a heavier tumor burden and worse physical condition during the COVID-19 pandemic, metastasectomy is recommended after the local HB has been resected $(35,36)$.

Recent research from SIOPLE compared the outcomes between children with HB who underwent R1 (microscopically margin-positive) resection and R0 (microscopically margin-negative) resection after hepatectomy (41). The results showed that the microscopic margin status had no obvious impact on the 5 -year survival rates of children with $\mathrm{HB}$ with effective chemotherapy (42). Another recent study from Asia also proved that a microscopically positive surgical margin did not seem to be associated with local recurrence and worse long-term survival outcomes in children with HB who underwent resection (43). During the pandemic, a "wait and see" strategy may be rational for children with $\mathrm{HB}$ that underwent R1 resection and showed normal AFP levels and 
imaging.

\section{Instruction for parents of HB children}

(I) Children may have poor compliance, so the parents should remind or help their children wash their hands frequently, wear a mask when going out, and cover their mouth/nose with a tissue or napkin when coughing or sneezing. It is reported that researchers from multiple organizations have successfully isolated novel coronavirus strains from stool specimens of infected patients $(44,45)$. Hence, extra attention should be paid to decrease the risk of fecal-oral transmission, especially for children who have not completed toilet training.

(II) Keep your children away from smoking and air pollution, which may influence the child's innate immune system and lead to underlying disorders (46). Preventing transmission by contact, respiratory droplets, aerosols, and the fecal-oral route can be achieved by: covering children's mouths and noses with a tissue or handkerchief when coughing or sneezing; regularly washing hands after returning from public places, using the restroom, and before eating; and teaching children not to touch their surroundings outside of the home (9). To reduce the risk of infection, children with $\mathrm{HB}$ should receive necessary treatment in the nearest hospital.

(III) Reduce anxiety and fear caused by COVID-19 or a deferred surgical schedule. Do not panic when confirming a SARS-CoV-2 infection, which is currently reported to have a low fatality rate in children (17). Appropriate postponement of surgery may not affect the prognosis of the child. If necessary, find an online psychological consultant for help.

\section{Conclusions}

In brief, we have tried to discuss the management plan of patients with $\mathrm{HB}$ during the current COVID-19 pandemic. Although studies on COVID-19 caused by SARS$\mathrm{CoV}-2$ infection have sprung up since the outbreak, many questions remain to be answered about COVID-19. During the last two decades, we have experienced three human coronaviruses worldwide, among which the COVID-19 pandemic is the most serious. We sincerely hope that pediatric surgeons can be protectors and defenders of children's health and play an important role in treating children suffering from pediatric surgical diseases while preventing the spread of infection during the current pandemic and future outbreaks of emerging infectious diseases.

\section{Acknowledgments}

Funding: The Special Fund of the Pediatric Medical Coordinated Development Center of Beijing Hospitals Authority (No. XTZD20180302) and Fundamental Research Funds for the Central University (No. 3332019166), China.

\section{Footnote}

Reporting Checklist: The authors have completed the Narrative Review reporting checklist. Available at http:// dx.doi.org/10.21037/tp-20-143

Conflicts of Interest: All authors have completed the ICMJE uniform disclosure form (available at http://dx.doi. org/10.21037/tp-20-143). The authors have no conflicts of interest to declare.

Ethical Statement: The authors are accountable for all aspects of the work in ensuring that questions related to the accuracy or integrity of any part of the work are appropriately investigated and resolved. This article does not contain any studies with human participants or animals performed by the author.

Open Access Statement: This is an Open Access article distributed in accordance with the Creative Commons Attribution-NonCommercial-NoDerivs 4.0 International License (CC BY-NC-ND 4.0), which permits the noncommercial replication and distribution of the article with the strict proviso that no changes or edits are made and the original work is properly cited (including links to both the formal publication through the relevant DOI and the license). See: https://creativecommons.org/licenses/by-nc-nd/4.0/.

\section{References}

1. World Health Organization. Coronavirus disease (COVID-2019) situation reports Available online: https://www.who.int/emergencies/diseases/novelcoronavirus-2019/situation-reports/

2. Lu R, Zhao X, Li J, et al. Genomic characterisation and 
epidemiology of 2019 novel coronavirus: implications for virus origins and receptor binding. Lancet 2020;395:565-74.

3. National Health Commission of the China home page. Available online: http://www.nhc.gov.cn

4. Feng J, Polychronidis G, Heger U, et al. Hoffmann K. Incidence trends and survival prediction of hepatoblastoma in children: a population-based study. Cancer Commun (Lond) 2019;39:62.

5. Cruz AT, Zeichner SL. COVID-19 in Children: Initial Characterization of the Pediatric Disease. Pediatrics 2020;145:e20200834.

6. Mao R, Liang J, Shen J, et al. Implications of COVID-19 for patients with pre-existing digestive diseases. Lancet Gastroenterol Hepatol 2020;5:425-7.

7. Chen ZM, Fu JF, Shu Q, et al. Diagnosis and treatment recommendations for pediatric respiratory infection caused by the 2019 novel coronavirus. World J Pediatr 2020;16:240-6.

8. Shen K, Yang Y, Wang T, et al. Diagnosis, treatment, and prevention of 2019 novel coronavirus infection in children: experts' consensus statement. World J Pediatr 2020;16:223-31.

9. Jin $\mathrm{YH}$, Cai L, Cheng ZS, et al. A rapid advice guideline for the diagnosis and treatment of 2019 novel coronavirus (2019-nCoV) infected pneumonia (standard version). Mil Med Res 2020;7:4.

10. Weldon CB, Madenci AL, Tiao GM, et al. Evaluation of the diagnostic biopsy approach for children with hepatoblastoma: A report from the children's oncology group AHEP 0731 liver tumor committee. J Pediatr Surg 2020;55:655-9.

11. Hishiki T, Watanabe K, Ida K, et al. The role of pulmonary metastasectomy for hepatoblastoma in children with metastasis at diagnosis: Results from the JPLT-2 study. J Pediatr Surg 2017;52:2051-5.

12. Xia W, Shao J, Guo Y, et al. Clinical and CT features in pediatric patients with COVID-19 infection: Different points from adults. Pediatr Pulmonol 2020;55:1169-74.

13. Towbin AJ, Meyers RL, Woodley H, et al. 2017 PRETEXT: radiologic staging system for primary hepatic malignancies of childhood revised for the Paediatric Hepatic International Tumour Trial (PHITT). Pediatr Radiol 2018;48:536-54.

14. Li Y, Guo F, Cao Y, et al. Insight into COVID-2019 for pediatricians. Pediatr Pulmonol 2020;55:E1-4.

15. Li W, Zhou Q, Tang Y, et al. Protocol for the development of a rapid advice guideline for prevention, management and care of children with 2019 novel coronavirus infection. Ann Palliat Med 2020;9:2251-5.

16. Lin L, Lu L, Cao W, Li T. Hypothesis for potential pathogenesis of SARS-CoV-2 infection-a review of immune changes in patients with viral pneumonia. Emerg Microbes Infect 2020;9:727-32.

17. Wu Z, McGoogan JM. Characteristics of and Important Lessons From the Coronavirus Disease 2019 (COVID-19) Outbreak in China: Summary of a Report of 72314 Cases From the Chinese Center for Disease Control and Prevention. JAMA 2020;323:1239-42.

18. Epidemiology Working Group for NCIP Epidemic Response, Chinese Center for Disease Control and Prevention. The epidemiological characteristics of an outbreak of 2019 novel coronavirus diseases (COVID-19) in China. Chinese Journal of Epidemiology 2020;41:145-51.

19. Chen J, Qi T, Liu L, et al. Clinical progression of patients with COVID-19 in Shanghai, China. J Infect 2020;80:e1-6.

20. Roebuck DJ, Aronson D, Clapuyt P, et al. 2005 PRETEXT: a revised staging system for primary malignant liver tumours of childhood developed by the SIOPEL group. Pediatr Radiol 2007;37:123-32; quiz 249-50.

21. Zsiros J, Brugieres L, Brock P, et al. Dose-dense cisplatinbased chemotherapy and surgery for children with highrisk hepatoblastoma (SIOPEL-4): a prospective, singlearm, feasibility study. Lancet Oncol 2013;14:834-42.

22. Deshpande G, Patel MD. Emergency hepatic resection a life saving procedure in ruptured hepatoblastoma: case report. Indian J Surg Oncol 2013;4:169-71.

23. General office of national health commission, Office of the state administration of traditional Chinese medicine. Diagnosis and management plan of pneumonia with new coronavirus infection (trial version 6). Available online: http://www.nhc.gov.cn

24. Meyers RL, Maibach R, Hiyama E, et al. Risk-stratified staging in paediatric hepatoblastoma: a unified analysis from the Children's Hepatic tumors International Collaboration. Lancet Oncol 2017;18:122-31.

25. Ueda M, Martins R, Hendrie PC, et al. Managing Cancer Care During the COVID-19 Pandemic: Agility and Collaboration Toward a Common Goal. J Natl Compr Canc Netw 2020. [Epub ahead of print]. doi: 10.6004/ jnccn.2020.7560.

26. Pritchard J, Brown J, Shafford E, et al. Cisplatin, doxorubicin, and delayed surgery for childhood 
hepatoblastoma: a successful approach--results of the first prospective study of the International Society of Pediatric Oncology. J Clin Oncol 2000;18:3819-28.

27. O'Neill AF, Towbin AJ, Krailo MD, et al. Characterization of Pulmonary Metastases in Children With Hepatoblastoma Treated on Children's Oncology Group Protocol AHEP0731 (The Treatment of Children With All Stages of Hepatoblastoma): A Report From the Children's Oncology Group. J Clin Oncol 2017;35:3465-73.

28. Malogolowkin MH, Katzenstein HM, Krailo M, et al. Treatment of hepatoblastoma: the North American cooperative group experience. Front Biosci (Elite Ed) 2012;4:1717-23.

29. Hiyama E, Hishiki T, Watanabe K, et al. Resectability and tumor response after preoperative chemotherapy in hepatoblastoma treated by the Japanese Study Group for Pediatric Liver Tumor (JPLT)-2 protocol. J Pediatr Surg 2016;51:2053-7.

30. Hishiki T, Matsunaga T, Sasaki F, et al. Outcome of hepatoblastomas treated using the Japanese Study Group for Pediatric Liver Tumor (JPLT) protocol-2: report from the JPLT. Pediatr Surg Int 2011;27:1-8.

31. Watanabe K. Current chemotherapeutic approaches for hepatoblastoma. Int J Clin Oncol 2013;18:955-61.

32. Katzenstein HM, Furman WL, Malogolowkin MH, et al. Upfront window vincristine/irinotecan treatment of high-risk hepatoblastoma: A report from the Children's Oncology Group AHEP0731 study committee. Cancer 2017;123:2360-7.

33. Chinese Anti-Cancer Association Pediatric Committee. Expert Consensus for Multidisciplinary Management of Hepatoblastoma (CCCG-HB-2016). Chin J Pediatr Surg 2017;38:733-9.

34. Czauderna P, Haeberle B, Hiyama E, et al. The Children's Hepatic tumors International Collaboration (CHIC): Novel global rare tumor database yields new prognostic factors in hepatoblastoma and becomes a research model. Eur J Cancer 2016;52:92-101.

35. Aronson DC, Meyers RL. Malignant tumors of the liver in children. Semin Pediatr Surg 2016;25:265-75.

Cite this article as: $\mathrm{Xu} \mathrm{H}$, Zhou Y, Sun R, Liu X, Diao M, Ren X, Li L. A narrative review of the challenges and countermeasures in hepatoblastoma management during COVID-19 epidemic. Transl Pediatr 2020;9(6):840-848. doi: $10.21037 /$ tp-20-143
36. López-Terrada D, Alaggio R, de Dávila MT, et al. Towards an international pediatric liver tumor consensus classification: proceedings of the Los Angeles COG liver tumors symposium. Mod Pathol 2014;27:472-91.

37. Meyers RL, Tiao G, de Ville de Goyet J, et al. Hepatoblastoma state of the art: pre-treatment extent of disease, surgical resection guidelines and the role of liver transplantation. Curr Opin Pediatr 2014;26:29-36.

38. Kumar D, Tellier R, Draker R, et al. Severe Acute Respiratory Syndrome (SARS) in a liver transplant recipient and guidelines for donor SARS screening. Am J Transplant 2003;3:977-81.

39. Yang T, Whitlock RS, Vasudevan SA. Surgical Management of Hepatoblastoma and Recent Advances. Cancers (Basel) 2019;11:1944.

40. Lake CM, Tiao GM, Bondoc AJ. Surgical management of locally-advanced and metastatic hepatoblastoma. Semin Pediatr Surg 2019;28:150856.

41. Ren X, Li H, Diao M, et al. Results of surgical resections with positive margins for children with hepatoblastoma: Case series from a single Asian center. Pediatr Blood Cancer 2019;66:e27479.

42. Aronson DC, Weeda VB, Maibach R, et al. Microscopically positive resection margin after hepatoblastoma resection: what is the impact on prognosis? A Childhood Liver Tumours Strategy Group (SIOPEL) report. Eur J Cancer 2019;106:126-32.

43. Ren X, Li H, Diao M, et al. Impact of microscopically margin-positive resection on survival in children with hepatoblastoma after hepatectomy: a retrospective cohort study. Int J Clin Oncol 2020;25:765-73.

44. Gao Y, Li T, Han M, et al. Diagnostic utility of clinical laboratory data determinations for patients with the severe COVID-19. J Med Virol 2020;92:791-6.

45. Ren X, Chen B, Hong Y, et al. The challenges in colorectal cancer management during COVID-19 epidemic. Ann Transl Med 2020;8:498.

46. Lee PI, Hu YL, Chen PY, et al. Are children less susceptible to COVID-19?. J Microbiol Immunol Infect 2020;53:371-2. 